\title{
Brincando de casinha: significado de família para crianças institucionalizadas $^{1}$
}

\author{
Edna Martins \\ Heloisa Szymanski \\ Pontifícia Universidade Católica de São Paulo
}

\begin{abstract}
Resumo
Este estudo teve o objetivo de investigar como a família é apresentada por crianças que vivem em uma instituição sob a responsabilidade do Estado. Participaram da pesquisa dez crianças com idades entre cinco e oito anos, sendo três meninos e sete meninas. Por meio de observação, foram analisados vários episódios de brincadeira livre das crianças, que se referiam à brincadeira de casinha numa sala de brinquedos da Febem de São Paulo. A análise dos dados apontou que, mesmo não estando com suas famílias, as crianças apresentaram uma família nos moldes do modelo nuclear.
\end{abstract}

Palavras-chave: brincadeira; criança; família; institucionalização

\begin{abstract}
Playing with the fantasy of home: the meaning of family for institutionalized children. This study aimed to investigate how family was presented during the games played by children living in an institution under the responsibility of the State. Ten children between five and eight years old took part in the investigation. There were three boys and seven girls. Through observation, several free playing episodes related to fancying a home were analyzed, in a playroom at Febem in São Paulo. The data analysis indicated that even under the circumstances of living outside home, those children presented a family based on the nuclear model.
\end{abstract}

Keywords: play; child; family; institutionalization

$\mathrm{N}$ ão parece fácil definir exatamente o que seja uma família. Para Fukui (1981), pode-se afirmar que não existe a família, mas uma diversidade de combinações circunscritas histórica e socialmente. O convívio entre as pessoas pode ser variado, indiferente ou não a "laços de sangue” e, mesmo assim, podemos defini-lo como um conjunto de relações familiares.

A atual família nuclear tornou-se modelo de estrutura familiar na grande maioria das sociedades industrializadas, caracterizado pela divisão dos papéis de homem e mulher, de pais e filhos, seguindo uma hierarquia de poder que é típica do seu funcionamento. Historicamente, essa proposta que rompe com modos e costumes de épocas anteriores, isola a família em seu lar, onde o marido e pai passa a ser o provedor do sustento da família; a mulher passa a responder pela vida doméstica e pela educação dos filhos, e estes, por sua vez, devem total obediência aos pais, como também devem a eles a sua educação, principal preocupação do casal (Ariés, 1973/ 1981; Poster, 1979).

Com o seu surgimento, a família nuclear trouxe consigo novos padrões de higiene e novos hábitos alimentares (principalmente para as crianças, no que se refere à amamentação), definindo novos rumos aos papéis da sexualidade e, conse- qüentemente, ao casamento e à vida afetiva (Ariés, 1973/1981). Outras transformações ainda ocorreram no seio da família nuclear. Algumas dessas mudanças se deram principalmente pela nova atitude da mulher e o seu papel na sociedade, inserindo-se no mercado de trabalho e, muitas vezes, sustentando toda a família. Seus filhos, que antes viviam exclusivamente sob seus cuidados, hoje cada vez mais precocemente, são obrigados a freqüentar creches, escolas e outras alternativas, que acabam atuando em sua educação.

Dois períodos marcam os estudos sobre a família desenvolvidos no Brasil a partir dos últimos 20 anos. Um desses períodos caracteriza-se pela tomada do modelo de família nuclear como referência para estudiosos do assunto. O segundo período é o que admite a preponderância do modelo de família nuclear, mas acredita na variação dos modos de funcionamento dentro deste modelo e a coexistência de outras diferentes formas de organização familiar, com outras características (Gomes, 1994).

Outro fator que deve ser considerado nos estudos sobre família é a diversidade de aspectos funcionais presentes no modelo em questão. As formas de funcionamento da chamada "família moderna" no Brasil se diferenciam drasticamente de uma região para outra e de uma classe social para outra, 
influenciadas pelos diversos fatores existentes em cada uma dessas esferas. É notável, por exemplo, a diferença entre o modo de funcionamento e os valores de uma família da zona rural e o de outra da zona urbana, que vive cercada de “tecnologias” diversas.

O que se quer evidenciar aqui é a compreensão da família, à qual se referiu Szymanski (1992) como um grupo de pessoas que convivem entre si numa relação duradoura, ocupando o mesmo espaço físico e social, com um tipo especial de relações interpessoais, com indivíduos que se respeitam, mantém vínculos afetivos, em que mães e pais educam seus filhos conjuntamente, ou com pessoas que mantêm um cuidado com os membros mais jovens ou mais idosos ou, ainda, cuidados mútuos entre si, independentemente de parentescos.

Sobre a denominação família, Gomes (1994) acrescenta que, a priori, a idéia de um padrão único de organização familiar que possa servir de modelo está descartada. Para a autora, “a família é aqui entendida, de acordo com a moderna historiografia, como uma instituição social básica, histórica, que se transforma sincrônica e diacronicamente” (p. 55), desvencilhando-se da idéia de família como algo natural.

\section{Breve consideração à história da infância e institucionalização}

A família tem sido apontada como uma das únicas possibilidades de desenvolvimento social e emocional para uma criança pequena. Porém, a história tem mostrado que, assim como a família se transformou no decorrer do tempo, a forma como a infância é vista e o modo de tratamento dispensado à criança foram sensivelmente modificados com o surgimento da família moderna. Ariès (1973/1981) fez grande contribuição para a história da infância e da família, através de estudos de documentos e da iconografia ao longo dos séculos como tentativa de se conhecer as sociedades tradicionais. $\mathrm{O}$ autor apontou que "foi necessária uma longa evolução para que o sentimento da infância realmente se arraigasse nas mentalidades" (Badinter, 1985, p. 53). Esses estudos mostram que, até o século XVII, a criança era vista como algo insignificante, tendo pouca importância para a própria família. A história da infância é, nesse período, marcada pelo abandono de crianças à própria sorte. “A passagem da criança pela família e pela sociedade era muito breve e muito insignificante para que tivesse tempo ou razão de forçar a memória e tocar a sensibilidade" (Ariès, 1973/1981, p. 10).

Como não havia, até meados do século XVII, um sentimento de infância semelhante ao contemporâneo entre as famílias, as crianças eram rejeitadas ou abandonadas aos montes. O abandono acontecia das mais variadas maneiras e contava cada vez mais com novos adeptos. A criança representava para as famílias um grande sacrifício e, “existia e ainda existe uma gama de soluções para esse problema, que vai do abandono físico ao abandono moral da criança. Do infanticídio à indiferença. Entre os dois extremos, possibilidades diversas e bastardas, cujos critérios de adoção são essencialmente econômicos.” Badinter (1985, p. 64).

Badinter (1985) aponta que o abandono até o século XVII não é respaldado somente nos problemas de ordem econômi- ca, mas muitas vezes no próprio egoísmo dos pais. Crianças eram abandonadas com bilhetes em suas vestes, dizendo particularidades de sua existência, talvez com a intenção de os pais voltarem a tê-las. Outras eram acompanhadas por enxovais luxuosos, que lhes permitiam identificar a sua origem social. De acordo com Poster (1979),

\begin{abstract}
A estrutura emocional do lar aristocrático só foi analisada por um punhado de historiadores. As crianças estavam nas mãos de fâmulos e criados desde o momento em que chegavam ao mundo. Pais e mães raramente se preocupavam com os filhos, especialmente durante os primeiros anos formativos. Os cuidados com os filhos eram considerados abaixo da dignidade de uma dama aristocrática. As crianças eram consideradas pequenos animais, não objetos de amor e afeição. (p. 198)
\end{abstract}

Com o triunfo do cristianismo, alguns valores éticos, como a preservação da vida, foram sendo fortalecidos. No entanto, por estabelecer rígidos padrões morais para a família, a Igreja provocou um aumento significativo do abandono, porque condenava o adultério e, conseqüentemente, os filhos bastardos que poderiam advir de relações pecaminosas, fora do casamento, poderiam manchar a honra de uma família (Mesgravis, 1976).

Nos tempos do Brasil colonial, e mesmo durante a época do Império, havia a roda. Instalada em orfanatos ou instituições religiosas, era um modo de abandonar crianças pequenas sem se saber a identidade de quem as abandonava. Inventado na Europa medieval, esse sistema funcionava por meio de um cilindro de madeira, denominado roda dos expostos, onde se depositavam as crianças enjeitadas, que mais tarde eram recolhidas por alguém da instituição ou orfanato.

Assim, em vez de abandonar o bebê indesejado pelos caminhos, bosques, praças, em latas de lixo, nas portas de igrejas ou casas de famílias, onde poderia morrer de frio, fome ou ser devorado por animais, colocavam-no de forma anônima na roda, onde ficava protegido. Essa forma de regime assistencial seguiu seu curso, estendendo-se até o período republicano e, em decorrência do crescente número de crianças abandonadas, foram sendo criados grandes orfanatos, patronatos e seminários, mantidos, sobretudo, por irmandades religiosas, onde as crianças eram atendidas coletivamente (Marcilio, 1997).

Em São Paulo, a Roda ou Casa dos Expostos foi criada em 1824, a exemplo das que funcionavam na Bahia e também no Rio de Janeiro. Até então as crianças enjeitadas eram atiradas em lugares públicos ou em monturos de lixo. Outras, ainda, eram criadas por parentes ou por particulares conhecidos pela sua caridade (Mesgravis, 1976).

O final do século XIX trouxe transformações. No Brasil, o contexto histórico e social deste período foi aprofundado nas análises de Mesgravis (1976), Rizzini (1993), Leite (1997) e Marcílio (1998), que apontam para um novo olhar em prol da causa do menor, constituindo novas políticas assistencialistas envolvendo preocupações médicas e jurídicas. A demanda acentuada de crianças pelas ruas ou abandonadas em praças ou portas de casas ou igrejas, e as altas taxas de mortalidade infantil, fizeram florescer a filantropia, resultando no surgi- 
mento de instituições para abrigo desses menores por todo o território nacional. No século XX, no Brasil, a preocupação com a infância "será expressa pela denúncia de médicos, juristas, educadores e jornalistas, de que a criança, basicamente a "criança pobre" é maltratada, seja qual for o seu habitat: a família, a rua, o asilo ou a fábrica” (Rizzini, 1993, p. 25).

Nesse século, parece começar a existir um modo mais humano de lidar com a criança e um novo sentimento de afeto é dedicado a ela. Entretanto, mesmo com tantas mudanças na forma como é tratada a infância até os dias de hoje, muitas crianças ainda sofrem maus tratos e são abandonadas pelos seus pais, o que, na maioria das vezes, resulta da miséria que assola muitas famílias.

No Brasil, atualmente, a proliferação de orfanatos ou casas de amparo a crianças abandonadas tem sido muito intensa. No entanto, apesar de se estar num tempo de grandes descobertas tecnológicas, progresso na medicina e ascensão industrial, não se teve grandes mudanças no tipo de atendimento que essas instituições oferecem.

\section{Algumas considerações sobre interação social e brincadeira}

Pesquisas como as de Bowlby (1951/1981) e Spitz (1979/ 1993) causaram grande impacto em toda uma época, polemizando o modo de ver o abandono na infância e o desenvolvimento da criança. No entanto, estudos posteriores começaram a questionar o que realmente acontecia com as crianças em estado de privação em instituições. Seria realmente apenas a privação materna o principal fator que causaria os sérios distúrbios no desenvolvimento da criança? Esses estudos acabaram por concluir que distúrbios nesta área poderiam ser causados por vários fatores, como a falta de estímulos ambientais e sociais, extremamente necessários à vida infantil (pois, normalmente, as instituições eram pobres, as paredes, por exemplo, se encontravam sempre vazias, sem nenhum estímulo visual, além de contarem com poucos adultos para cuidar de muitas crianças), ou a falta de alimentação adequada.

Um estudo clássico de Freud e Burlingham (1960), com crianças órfãs de guerra criadas em abrigos, começou a dar pistas de algumas possibilidades para melhorar o atendimento em instituições para menores. Apesar de estarem separadas de suas mães, viverem sob cuidados múltiplos e em situação de privação de estímulos ambientais, as crianças voltavam-se para contatos com parceiros em igual situação de vida. Vivendo juntamente com outras crianças de idades variadas, os internos das instituições se envolviam em parcerias uns com os outros e aprendiam a interagir mais precocemente. Entre essas crianças, observaram-se freqüentemente comportamentos de cuidado mútuo, consolo e auxílio em várias situações de vida.

Esses elementos podem ser observados nessas interações, que em muitas situações se dão na forma de brincadeira, uma das mais ricas maneiras de trocas sociais, pois a criança acaba se envolvendo com seus parceiros e usufruindo, clara e concretamente, de uma possibilidade prazerosa e vital de convivência humana em grupo.
Mesmo sem uma ação planejada, as instituições são capazes de fornecer a possibilidade de crianças se desenvolverem socioemocionalmente, na medida em que interagem em relações que significam vínculos essenciais entre seres que estão crescendo e buscando a sua legítima inserção numa mesma sociedade. Nesse caso, a interação social se dá essencialmente nos momentos de brincadeiras livres em que as crianças podem realizar trocas variadas. Compactuando com pesquisas que mostraram que o mundo de faz-de-conta vivido pela criança, quando inserida num espaço de brincadeiras ou mesmo envolvida com as regras de qualquer jogo infantil, pode representar um fio condutor para o aprendizado, como também uma valiosa experiência emocional, física e social para crianças pequenas (Brougère, 1997, 1998; Elkonin, 1998; Kishimoto, 1997, 1998; Oliveira, 1988; Vygotsky, 1994) é possível justificar a posição de que mesmo a criança que não vive em sua família de origem pode estabelecer, a partir da brincadeira, alguns padrões de interação que dão conta de representar aquilo que para ela tem tal significado.

De um modo geral, quando as crianças brincam, elas interagem o tempo todo, influenciando e sendo influenciadas pelos outros membros do grupo. Nesta interação, experimentam papéis diferentes e têm suas ações delimitadas pelas ações do grupo como um todo. Nesta troca, experimentam uma variedade de atitudes sociais, reproduzem práticas que observam entre os adultos e podem, assim, aprender a importância das relações entre os humanos e, sobretudo, o mundo de coisas que envolvem o viver em sociedade. Uma criança, quando envolvida numa brincadeira de faz-de-conta, como, por exemplo, quando usa sua imaginação para brincar com outras crianças de papai, mamãe e filhos, distribuindo papéis e incorporando outros, pode experienciar significados que já ocorreram de alguma forma no seu cotidiano, como também construir algum significado que para ela é importante naquele momento de interação social.

De uma forma ou de outra, quando inseridas num momento de brincadeira, as crianças realizam entre si um tipo de interação social que é de suma importância para a formação delas enquanto pessoas, realizando trocas variadas quando riem, se desentendem, choram ou trocam carinhos que só são possíveis numa situação imaginária.

Vygotsky foi um importante autor no estudo das interações infantis e do brincar, mas não é objetivo aprofundar considerações sobre suas idéias, vale ressaltar que para esse pesquisador, o brincar, além de estar repleto de significados para a criança, constitui importante fator para o desenvolvimento cognitivo infantil. Quando uma criança brinca com um ou mais parceiros, além de interagir de forma intensa com os outros, ela também compartilha o prazer da brincadeira e, ao mesmo tempo, incorpora uma infinidade de elementos do mundo objetivo. Com a situação de faz-de-conta, a criança pode lançar mão do real e do imaginário, sempre envolvida numa condição de regras (Vygotsky, 1994).

A situação imaginária de qualquer forma de brinquedo já contém regras de comportamento, embora possa não ser um jogo com regras formais estabelecidas a priori. A criança imagina-se como 
mãe e a boneca como criança e, dessa forma, deve obedecer as regras do comportamento maternal. (Vygotsky, 1994, p. 124)

Entendendo a brincadeira como uma atividade privilegiada para se observar o desenvolvimento da criança, suas habilidades sociais, seus sentimentos, suas expressões e sua organização cognitiva da experiência, utilizou-se na pesquisa relatada a seguir, a brincadeira como um recurso metodológico de observação em ambientes naturais, com a pretensão de se estudar o significado de família para crianças privadas do convívio com suas famílias de origem.

\section{Método}

O estudo foi realizado na Febem (Fundação do Bem-Estar do Menor), especificamente na Unidade Sampaio Viana, no bairro do Pacaembu, em São Paulo, no ano de 1997. Nesse mesmo ano, essa unidade, que teria sobrevivido durante mais de 100 anos, foi desativada e as crianças foram encaminhadas para pequenos abrigos inseridos dentro de algumas comunidades, com capacidade máxima para 80 crianças, possibilitando um atendimento mais individualizado. A instituição abrigava crianças de até 8 anos, encaminhadas pela justiça por estarem abandonadas ou sofrendo maus tratos por parte de suas famílias de origem. Algumas permaneciam no local até que pudessem retornar para seus lares, acompanhadas por programas de apoio familiar. Outras, porém, depois de algum tempo, sem haver a possibilidade de integrá-las a suas famílias (por vários motivos, dentre eles o completo abandono) eram entregues para a adoção.

\section{As crianças participantes}

A pesquisa foi realizada com um grupo de dez crianças, escolhidas aleatoriamente, mas que estavam internas na insti- tuição há pelo menos um mês. As idades variavam entre cinco e oito anos. Para garantir a segurança delas, seus nomes foram trocados por outros fictícios. Casualmente, nenhuma era alfabetizada e naquele momento não freqüentava a escola.

Os dados registrados na Tabela 1 foram extraídos dos prontuários que são elaborados pelos técnicos da Febem, o que pode indicar uma caracterização vista por alguns como preconceituosa, já que aponta, na maioria das vezes, para dados que podem denegrir a imagem da família de origem dessas crianças. De acordo com esses técnicos, tais informações são obtidas em entrevistas com a família ou com outros responsáveis pela criança. Certos dados, como a idade de algumas, que se encontram em total estado de abandono, ou que nunca foram registradas oficialmente pelas suas famílias, são colocados de uma forma aproximada por profissionais da área de saúde, que realizam exames dentários e alguns outros exames capazes de demonstrar aproximadamente a época em que se deu o nascimento.

Algumas crianças encaminhadas pela Polícia quando encontradas perambulando pela cidade, tiveram suas imagens exibidas em programas de televisão, mas ninguém as havia procurado até o momento da pesquisa. Outras sabiam o local em que a família residia, mas, por algum motivo, demoravam meses para dar alguma pista desses lugares, dificultando possibilidades na obtenção de alguma informação a respeito delas.

\section{Procedimentos para coleta de dados}

Pela dificuldade encontrada em se obter relatos verbais de crianças pequenas sobre o significado de família, utilizando instrumentos como a entrevista e, pela própria natureza da questão investigada, optou-se, então, pelo uso do jogo simbólico ou brincadeira de faz-de-conta como procedimento

Tabela 1

Dados sobre as crianças participantes

\begin{tabular}{|c|c|c|c|}
\hline Nome & Idade & Família (pai/mãe/irmãos) & Motivo para o encaminhamento \\
\hline Carla & 5 anos & Pai: usuário de drogas & Segundo a Polícia, pediam esmola \\
\hline Cris & 7 anos & $\begin{array}{l}\text { Mãe: faxineira } \\
\text { Irmãos: dois meninos }\end{array}$ & \\
\hline Alê & 6 anos & Pai e mães desconhecidos & $\begin{array}{l}\text { Segundo a Polícia, estava perdida } \\
\text { na cidade }\end{array}$ \\
\hline Zeca & 7 anos & $\begin{array}{l}\text { Pai: alcoólatra (separado da mãe) } \\
\text { Mãe: trabalha em indústria } \\
\text { Irmãos: três }\end{array}$ & $\begin{array}{l}\text { Segundo a Polícia, perambulava } \\
\text { pela cidade }\end{array}$ \\
\hline Rose & 7 anos & $\begin{array}{l}\text { Pai: desconhecido } \\
\text { Mãe: alcoólatra, desempregada } \\
\text { Irmãos: Mais cinco (internos) }\end{array}$ & $\begin{array}{l}\text { Foi encaminhada ao Juizado de } \\
\text { Menores por maus tratos da } \\
\text { família }\end{array}$ \\
\hline Ane & 6 anos & $\begin{array}{l}\text { Pai: usuário de crack e álcool } \\
\text { Mãe: desempregada } \\
\text { Irmãos: quatro internos e dez com outras } \\
\text { famílias }\end{array}$ & $\begin{array}{l}\text { Segundo a Polícia, foi encontrada } \\
\text { em operação em farol (crianças } \\
\text { junto com usuários de drogas) }\end{array}$ \\
\hline Mara & 5 anos & $\begin{array}{l}\text { Pai: presidiário } \\
\text { Mãe: usuária de drogas (ex-interna da Febem) } \\
\text { Irmãos: dois (internos) }\end{array}$ & $\begin{array}{l}\text { Por meio de denúncia ao Juizado } \\
\text { de menores (crianças eram } \\
\text { mantidas trancadas sozinhas } \\
\text { durante o dia todo) }\end{array}$ \\
\hline Tito & 7 anos & Pai e mãe desconhecidos & Polícia (perdido na cidade) \\
\hline Fanny & 8 anos & Mãe: usuária de drogas (assassinada) & Polícia (perambulavam pelas ruas) \\
\hline João & 7 anos & $\begin{array}{l}\text { Pai: presidiário } \\
\text { Irmãos: dois (internos) }\end{array}$ & \\
\hline
\end{tabular}


investigativo. Para a coleta dos dados, foi escolhida a técnica de observação em situações de brincadeira, utilizando-se equipamentos de câmera de vídeo e gravador para o registro de episódios interativos e falas. As crianças foram observadas em grupo, apenas por uma pesquisadora, que, próxima delas, filmou episódios de brincadeiras simbólicas.

Inicialmente, foram realizadas seis observações assistemáticas de aproximadamente uma hora cada, sempre no período da manhã, em vários ambientes da instituição, sem utilização de qualquer equipamento, com todas as crianças. Foi realizada, também, uma sessão sistemática de gravação num período de 30 minutos, já com o pequeno grupo participante do estudo, para adaptação das crianças ao equipamento de filmagem, e com a presença da pesquisadora.

Num segundo momento, foram feitas duas sessões de 15 minutos numa sala de brinquedos da instituição, onde é comum as crianças passarem algum período do dia. Lá havia vários brinquedos de muitos tipos: algumas cadeiras, mesa e alguns caixotes de madeira, todos adequados ao tamanho das crianças. Elas foram orientadas a brincar como de costume com todos os brinquedos disponíveis na sala. Muitos deles lembravam a brincadeira de casinha, como telefones, pratos e talheres, bonecas, etc.

Além do grupo de dez crianças, uma professora as acompanhava, a qual também foi observada em suas intervenções e interações na própria situação de faz-de-conta.

\section{A aplicação da grounded-theory como método de análise de dados}

A transcrição da filmagem aconteceu registrando-se todas as falas e ações desenvolvidas na brincadeira pelas crianças na seqüência em que elas aconteciam, de forma a englobar tudo o que havia sido filmado. Todas as dez crianças que participaram do momento do faz-de-conta, de alguma forma, assumiram determinados papéis ou personagens diferentes.

Os textos resultantes da transcrição dos registros filmados foram analisados segundo a grounded-theory, ou teoria fundamentada nos dados, proposta por Glaser e Strauss (1967). A grounded-theory é um método de análise qualitativa de dados, particularmente sensível a contextos, que é capaz de permitir a compreensão do sentido de determinadas situações, ou fenômenos sociais. O uso deste método foi primordial neste estudo com crianças no contexto onde elas viviam e interagiam cotidianamente. A inovação e grande contribuição desta proposta de análise é construir uma teoria confiável, capaz de "clarear" o fenômeno estudado em suas múltiplas facetas. A grounded-theory utiliza-se de procedimentos que foram elaborados de maneira normativa, em etapas diferenciadas e sucessivas, obedecendo aos rigores dos critérios do método científico.

Para esse processo foram realizadas várias transcrições do vídeo e a elaboração das categorias, de acordo com a grounded-theory. Ela prevê um processo contínuo de retorno aos dados até que se defina uma categoria que agrupe dados com afinidades entre si.

Sucintamente, apresentam-se os passos seguidos para a análise dos dados, segundo a grounded-theory:
1. Interação com os dados propriamente ditos, de maneira a favorecer um verdadeiro "mergulho" no corpo de dados obtidos.

2. Processo de codificação, quando os dados são desmembrados, examinados, comparados cuidadosamente e finalmente, codificados de acordo com sua especificidade.

3. Criação das categorias, que devem ser nomeadas de forma abstrata e de maneira a apresentar uma força conceitual.

4. Realização da codificação axial, definida como "um conjunto de procedimentos em que os dados são agrupados de novas formas, através das conexões entre as categorias. Isso é feito através do uso de um paradigma de codificação que envolve condições, contexto, estratégias de ação/ interação e conseqüências” (Strauss \& Corbin, 1990, p. 96).

5. Descobrir a categoria central, definida por Strauss e Corbin (1990) como “o fenômeno central, ao redor do qual todas as outras categorias se integram” (p. 96).

A categoria central foi nomeada de Brincando de Casinha, englobando as categorias: Família brincada; Interações entre os membros da família brincada; e $\mathrm{O}$ adulto e o faz-deconta infantil, que representaram o fenômeno em questão de acordo com cada momento de brincadeira.

A seguir, apresentam-se os dados já organizados em suas categorias e subcategorias citadas anteriormente.

\section{Resultados e análise}

Todas as dez crianças que participaram do momento do faz-de-conta, de alguma forma, assumiram determinados papéis ou personagens diferentes. Mesmo aquelas que muito pouco se expressaram no grupo ou permaneceram isoladas durante grande parte da brincadeira, tiveram um tipo de postura, típica de um ou de outro personagem, que vale a pena explicitar para analisar o momento lúdico.

A brincadeira de faz-de-conta aconteceu como um grande jogo de interpretações de papéis. Neste momento pôde-se verificar a existência de personagens mutantes de uma criança para outra, ou mesmo um tipo de papel assumido por alguém, desde o início da brincadeira até o seu fim. Algumas crianças se expressaram mais, na medida em que seus personagens exigiam, outras se limitaram a vivenciar personagens menos ativos, mas tão importantes quanto aqueles, desenvolvendo uma dinâmica própria das relações sociais que permeiam a existência humana.

Essa dinâmica de representações de papéis durante a brincadeira seguiu um aglomerado de regras e padrões de conduta, propiciando ao grupo a possibilidade de experimentar diferentes "vestimentas" de variados modos de ser com o outro, num mundo essencialmente construído pelo aspecto social.

\section{Discussão}

\section{A família brincada}

O que se observou, de um modo geral, foi que a família apresentada segue o modelo de família conhecido pelas crianças no breve decorrer de suas vidas, tanto fora como inter- 
Tabela 2

Comportamentos e desenvolvimento de papéis

\begin{tabular}{clll}
\hline Criança & \multicolumn{1}{c}{ Comportamento } & \multicolumn{1}{c}{ Papel } & \multicolumn{1}{c}{ Postura } \\
\hline Fanny & $\begin{array}{l}\text { Deu ordens, coordenou o grupo, arrumou a } \\
\text { casa, fez comida e serviu família }\end{array}$ & $\begin{array}{l}\text { Esposa e mãe } \\
\text { ordenadora }\end{array}$ & Coordenação geral \\
\hline João & $\begin{array}{l}\text { Interagiu com todos, ajudou a organizar a casa } \\
\text { e servir família, obedeceu ordens }\end{array}$ & $\begin{array}{l}\text { Pai e marido } \\
\text { trabalhador }\end{array}$ & $\begin{array}{l}\text { Assessoria e } \\
\text { coordenação }\end{array}$ \\
\hline Tito & $\begin{array}{l}\text { Interagiu com os meninos, obedeceu as ordens } \\
\text { dos pais }\end{array}$ & Filho e irmão & Passiva \\
\hline Zeca & Interagiu mais com Tito & Filho e irmão & Passiva \\
\hline Ane & Organizou a casa e brincou com irmãos & Filha & $\begin{array}{l}\text { Interessada nas } \\
\text { coisas da casa }\end{array}$ \\
\hline Carla & $\begin{array}{l}\text { Brincou com bonecas, interagiu mais com } \\
\text { objetos, falou baixo e pouco }\end{array}$ & Filha menor & Acatadora de ordens \\
\hline Cris & $\begin{array}{l}\text { Interagiu com todos, ajudou a mãe no cuidado } \\
\text { com filhos }\end{array}$ & $\begin{array}{l}\text { Ora mãe e maior } \\
\text { parte do tempo } \\
\text { filha }\end{array}$ & $\begin{array}{l}\text { Ativa e aliada de } \\
\text { Fanny }\end{array}$ \\
\hline Rose & $\begin{array}{l}\text { Tentou todo o tempo agradar a mãe, mas } \\
\text { sempre a desagradou. Disputou objetos com as } \\
\text { outras crianças }\end{array}$ & Filha & $\begin{array}{l}\text { Ativa, tentando } \\
\text { agradar mãe }\end{array}$ \\
\hline Alê & $\begin{array}{l}\text { Pareceu ausente, esperou as ordens da mãe, } \\
\text { cuidou muito tempo das bonecas. Isolada do } \\
\text { grupo, falou baixo e pouco }\end{array}$ & Filha & Passiva e distante \\
\hline Mara & $\begin{array}{l}\text { Obedeceu as ordens da mãe e do pai e } \\
\text { interagiu com as meninas que ficaram com as } \\
\text { bonecas }\end{array}$ & Filha & Ativa e acolhedora \\
\hline
\end{tabular}

namente na instituição, por diferentes veículos de comunicação. No início da brincadeira, as crianças começaram a construir no faz-de-conta uma “constituição de família” muito parecida com a família nuclear que todos conhecem.

João e Fanny - duas crianças mais velhas e também irmãos - construíram um enredo e fantasiaram a experiência de serem casados. O enredo sobre ser marido e esposa foi criado e desenvolvido pelas próprias crianças e reforçado pela professora, que interferiu em alguns momentos.

Como é comum em nossa sociedade, na família nuclear existe um casal representado pela figura do pai e da mãe, que se casam para ter filhos e constituir um grupo familiar. $\mathrm{Na}$ família brincada por Fanny e João, isto também ocorreu. João é marido de Fanny e, portanto, usam um anel ou aliança que, encontrado no meio dos brinquedos que têm disponíveis, simboliza para eles o enlace.

Na família vivida de Fanny, João é seu irmão, mas na sua família do faz-de-conta transformou-se magicamente em seu marido. Os dois pareciam ter, durante toda a brincadeira, uma confiança mútua, coisas da vida real misturadas ao mundo fantasioso.
Nessa família brincada, como nas outras dimensões de família da criança, a figura de pai e de mãe ocupou um lugar privilegiado. Como estão no topo de uma hierarquia, a autoridade é deles. Suas ordens e seus desejos eram, na maioria das vezes, atendidos no espaço lúdico. Aqui, pai e mãe, homem e mulher também tinham funções parecidas com as da realidade. O pai, ou o homem da casa, devia trabalhar fora e trazer o sustento para a família, e a mãe e as outras mulheres deviam cuidar da casa e servir a família incansavelmente.

O papel que Fanny construiu e assumiu neste faz-de-conta foi muito parecido com o papel de muitas mulheres de nossa sociedade. Representou uma personagem muito comum nos lares brasileiros, tendo como base os fatos da vida cotidiana.

As crianças coordenaram episódios que giraram em torno de um jantar em família, e mostraram que essa família brincada é verdadeiramente um grupo de convivência especial, que respeita uma hierarquia, “organiza rotinas”, ajuda-se mutuamente, comunica-se de forma clara e diverte-se com os companheiros, demonstrando prazer em viver este faz-deconta tão real, o que, para essas crianças, significa possibilidades de experimentar uma vida familiar harmoniosa.

Tabela 3

Representação das categorias e subcategorias analisadas

\begin{tabular}{ll}
\hline \multicolumn{1}{c}{ Categorias } & \multicolumn{1}{c}{ Subcategorias } \\
\hline A família brincada & Constituição da família (pai, mãe, filhos, irmãos) \\
& Hierarquia na família \\
& Organização das rotinas \\
& Desenvolvimento e representação de papéis \\
\hline Interação entre os membros & Interações sociais entre crianças \\
da família brincada & Focalização de comportamentos de agressão, \\
& cooperação e cuidado mútuo \\
\hline $\begin{array}{l}\text { O adulto e o faz-de-conta } \\
\text { infantil }\end{array}$ & Interação da professora com o grupo de brincadeira \\
\hline
\end{tabular}


Como essas crianças já viveram experiências múltiplas com a família de origem, algumas experiências de vida na rua e na instituição, o quociente de vivência e de possibilidades de vida social que elas carregam é demasiado grande. Portanto, na família brincada ocorreram momentos que pareciam, às vezes, tipicamente de grupo familiar e, ao mesmo tempo, tinham muito de institucional. Como, por exemplo, o momento em que vivenciaram regras impostas por adultos, como o dever de comer verduras ou o de rezar antes das refeições.

Para Fanny, a sua posição como mãe foi privilegiada e, desse modo, merecia algumas condições ou tratamentos que só os adultos podiam ter. Para ela e João, deveria ser tudo muito melhor do que para as outras crianças, que estavam num papel de submissão, como filhos do casal. Prova disso é que escolheu os melhores utensílios de cozinha para eles e depois que os filhos jantaram, eles puderam sair de casa para passear.

João e Fanny representaram o papel de adultos e, além disso, o papel de pai e mãe, que, na perspectiva hierárquica de uma família, ocupam o topo da escala. As outras crianças, além de terem ocupado papéis que representavam quase a sua própria idade, fizeram o papel de filhos, submetendo-se às ordens e desejos de seus superiores hierárquicos.

Sob este prisma, entendendo que a criança, ao brincar, exterioriza um misto do que ela vive ou viveu com aquilo que ela pensa, imagina ou cria interiormente, é possível, por isso, se chamar a sua família do faz-de-conta de família brincada.

Essa família brincada, se assim se pode chamá-la, é construída no decorrer de uma fantasia que, em si, vem repleta de conteúdos vividos pela criança durante toda a sua vida. Essa fantasia, que é também conhecida como faz-de-conta, pode tomar variadas formas e, por mais confusa que seja, sempre terá em sua estrutura uma regra que é própria do mundo real da criança. Isso foi verificado em todos os momentos da brincadeira, em que as crianças repetiram padrões de comportamentos típicos do modelo de família vigente em nossa sociedade.

\section{Interações entre os membros da família brincada}

Na instituição, com a riqueza de interações sociais entre parceiros de idades e sexos diferentes, a maioria das crianças é quase obrigada pelas circunstâncias a aprender rapidamente a agir de forma adequada nos momentos em que poderia pedir a ajuda de um adulto ou tomar atitudes agressivas para resolver alguma questão.

Geralmente, as crianças têm problemas de relacionamento umas com as outras, ocasionados, principalmente, pela disputa de objetos ou de poder. Nesses casos, quando não há um adulto por perto, podem agir de forma a negociar com o outro e resolver o problema, garantindo a continuidade harmoniosa do momento de interação em que estão vivendo.

A família do faz-de-conta, em momentos de interação, acabou utilizando meios para se organizar que são muito comuns entre as crianças, mesmo quando não estão em momentos de brincadeira. Em alguns momentos foi possível verificar modalidades de interação que permearam toda a construção do enredo da brincadeira, a forma de relação social do grupo de crianças que brincavam, como também do grupo familiar imaginário.
A agressão, observada em alguns breves momentos dentro do grupo, parece ter uma função importante no momento lúdico, como a de definir papéis ou organizar uma hierarquia de poder entre os membros da brincadeira ou, ainda, como um mero recurso para solução de problemas entre as crianças, como a disputa de objetos.

Outras soluções também pareceram oportunas na solução de pequenos desentendimentos. No caso da brincadeira, a mãe fictícia também serve de ajuda na solução de algumas questões. Em alguns episódios, as crianças utilizaram pouca linguagem verbal e seus gestos e atitudes eram o que mais nos revelava sobre o que estava ocorrendo.

Na situação de grupo em que as crianças da instituição se encontram é comum que elas cooperem umas com as outras em atividades da vida diária. Quando estão brincando, podemos observar alguns tipos de cooperação entre elas. A ajuda mútua tem sempre um objetivo para as crianças envolvidas na interação e essa troca social é muito importante para o seu desenvolvimento como pessoa.

A cooperação, ou ajuda mútua, permeou a grande maioria das interações da brincadeira de faz-de-conta. As crianças se organizaram dentro da família, cooperando com a organização da casa ou auxiliando uns aos outros em momentos variados.

Observaram-se também, no contexto da brincadeira de faz-de-conta, comportamentos ou atitudes que revelaram os cuidados de uma criança com a outra ou, ainda, os cuidados de uma criança que atuava em determinado papel de adulto (pai ou mãe), preocupando-se claramente com outras crianças, servindo-as, colocando regras para as suas vidas e atuando como os adultos quando cuidam de crianças. Puderamse notar também comportamentos de cuidado ligados às bonecas, como dar banho, pentear, trocar e dar mamadeira.

Em alguns momentos, tanto a mãe da família do faz-deconta serviu à família e cuidou dos filhos, como as meninas sentadas à mesa se preocuparam com as bonecas (os bebês), dizendo que elas também tinham que mamar. Pode-se afirmar, portanto, que o brincar de cuidar está relacionado tanto à interação entre as crianças do grupo de brincadeira como também aos objetos que têm o significado de crianças, ou bebês para o grupo. Nesta brincadeira, a criança mimetizou o trabalho de cuidado e proteção adulto-criança, experimentando de maneira clara algumas atitudes adultas.

Na instituição, mesmo tendo condições de resolver seus problemas triviais na interação com outros companheiros, em muitos momentos, a criança pede a ajuda de um adulto. Entretanto, como essa ajuda tarda a chegar ou às vezes nem chega, ela acaba por solucionar a questão sozinha, ou em parceria com crianças da mesma idade ou um pouco maiores. Nestes casos, o descuido dos adultos, tanto na família de origem quanto na instituição, acaba por desenvolver uma condição de cuidados mútuos entre as próprias crianças.

\section{$O$ adulto e o faz-de-conta infantil}

Para que as brincadeiras infantis sejam momentos de ricas experiências de aprendizagem, é preciso que o ambiente em que as crianças estejam contribua para isso. Evidentemente que as crianças são capazes de transformar ambientes com 
poucos objetos ou nenhum em locais agradáveis para realizar brincadeiras divertidas e interessantes. Num pátio, por exemplo, elas podem pegar pedrinhas, folhinhas e gravetos e criar uma infinidade de possibilidades de brinquedos. Podem também criar brincadeiras que utilizem o próprio corpo ou a voz. No entanto, quanto mais bem organizado for o ambiente, maior será a garantia de que a criança encontre momentos propiciadores de aprendizagem disponíveis na brincadeira.

A presença do educador também é muito importante para dar um suporte e acompanhar as crianças no decorrer de suas interações. Oliveira (1995) afirma que a presença de um adulto em contato com as crianças pode ser de grande valia nas brincadeiras. A autora coloca que acreditar que as brincadeiras livres podem ter sucesso sem o acompanhamento de um adulto significa negar todo o conhecimento acumulado até hoje. O adulto pode ajudar as crianças numa brincadeira de faz-de-conta, por exemplo, a trabalhar conteúdos, resolvendo pequenos conflitos entre elas e cuidando da organização do espaço e dos brinquedos.

Neste trabalho, a professora que acompanhava o grupo de crianças em suas brincadeiras diárias esteve presente em duas das sessões de filmagens. Sua presença foi importante no sentido de sistematizar regras de comportamento, ou administrar conflitos. Entretanto, por algumas vezes as suas intervenções pouco funcionaram, pois não foi o tempo todo que as crianças aceitaram suas opiniões, especialmente quando ela indicava a direção da brincadeira. Parece comum que a professora deixe as crianças brincarem livremente na sala de brinquedos da instituição, sem fazer muitas intervenções ou observações. Isso foi verificado durante os dias em que a pesquisadora passou na Casa.

Quando a brincadeira era registrada em vídeo, a professora, além de ficar apenas observando, tentou fazer algumas interferências. Num primeiro momento, tentou organizar a brincadeira, da forma que, para ela, parecia mais “adequada”. No espaço em que algumas crianças montavam uma espécie de casinha, ela interferiu dizendo para uma delas que não poderia brincar de palhaço no meio de uma casinha de bonecas, pois não queria que houvesse influências de outras brincadeiras ou que algumas crianças atrapalhassem a brincadeira de casinha, mas isso pouco adiantou. A criança insistiu por mais duas vezes em brincar de palhaço, mas não houve espaço ou incorporação da brincadeira no faz-de-conta do grupo. A professora tentou também, de forma mais democrática, colocar algumas regras na brincadeira por intermédio de um acordo. Deixou claro que não era proibido brincar de palhaço e de bolinha, mas existia um modo de fazer isso sem atrapalhar a brincadeira dos outros. As crianças não responderam nada para a professora, que foi novamente ignorada. Isso fica claro na descrição da cena a seguir:

Perto de onde pode ser identificado como a cozinha da casinha, Ane brinca com uma batedeira de bolos, enquanto Fanny arruma os utensílios sobre os módulos. Neste momento, a professora interrompe a brincadeira quase gritando: "Vamos fazer um trato? Quem quer brincar de bolinha vem brincar aqui. Quem quer brincar de bolinha e de palhaço vem brincar pra cá”. Ninguém obedece à professora. Rose apenas retira o nariz de palhaço, coloca os óculos sobre a cabeça e dá uma olhada para a filmadora, depois volta a colocar os óculos e fica penteando o seu próprio cabelo numa posição de quase auto-admiração. Carla pega a mão biônica e continua brincando no meio da casinha, pegando objetos do chão e levantando para o alto.

No decorrer da brincadeira, a professora continuou tentando interagir com o grupo, colocando ordem em tudo. Num certo momento, fez uma observação para que as crianças arrumassem a casa e tirassem uma caixa de papelão do meio da cozinha. Ela continuou todo o tempo tentando insistentemente ensinar às crianças algumas regras de nossa vida social, mas foi quase sempre ignorada pelas crianças, que continuavam brincando. Não contente com a situação, foi além da comunicação verbal, pois percebeu que não estava sendo ouvida. Desse modo, invadiu o espaço lúdico na intenção de deixar tudo organizado.

A professora entra em cena e vai retirando vários brinquedos que estão sobre a mesa em que os meninos estão sendo servidos, dizendo: “Ah, pra servir a comida vocês nem arrumaram a mesa, hein?”. Ane diz logo em seguida, parecendo não se importar muito com a professora: "Eu vou servir”. Quando acaba de colocar o prato na frente de Tito, ele grita: "E a salada? E o tomate?”. Na mesma hora alguém grita da cozinha: “O tomate já tá fazendo!”. Outra criança pergunta espantada: “Tomate?”. E todos continuam brincando sem se importarem com a caixa de papelão que a professora havia mandado tirar do meio da cozinha.

Quando a professora entrou no meio da brincadeira de faz-de-conta das crianças não se comportou como uma personagem, pelo contrário, atuou como um adulto interessado apenas em explicitar regras para se "viver melhor". Entretanto, não se dirigiu às crianças tratando-as como elas mesmas, mas como as personagens de um enredo que estava sendo construído desde o início da brincadeira. Ela tentou fazer uma ponte bastante estreita entre o mundo real e o imaginário, pois não se deixou envolver totalmente com aquele momento lúdico que as crianças estavam vivendo.

Mesmo com a entrada abrupta da professora em cena, sem que ninguém do grupo desse a ela uma "deixa”, as crianças não se dispersaram e continuaram envolvidas num mundo particular em que eram válidas as suas regras, que estavam sendo vividas num mundo imaginário, que, por sua vez, pertencia a um mundo social inserido numa determinada cultura. Assim, continuaram a brincadeira como se ninguém tivesse interferido neste mundo de fantasia.

Quando a professora fez a intervenção no momento correto da brincadeira, como no episódio seguinte, a sua ação se mostrou muito eficaz e nessa hora as crianças aceitaram as suas colocações e acabaram de alguma forma assimilando aquilo que lhes foi passado no espaço lúdico.

Fanny continua colocando os pratos na mesa de um em um para cada criança. A professora, que observa a cena, diz: “Ô, marido! Ajuda a sua mulher a pôr a mesa”. João se levanta imediatamente e começa a querer ajudar Fanny a distribuir os 
pratos, mas é interrompido por ela, que grita: "Vão lavar as mãos antes de comer, vão!?”. Algumas crianças, sem se levantarem da mesa, fazem apenas gestos de que estão lavando as mãos e vão logo dizendo: "Já lavei as mãos”. A professora diz: "Lavar é no banheiro, né? Vai lavar a mão. (...) O banheiro pode ser num cantinho”. Agora quase todos se levantam (com exceção de dois), vão até um canto da parede e fazem gestos rápidos de lavar as mãos. No mesmo momento, Fanny grita: “Quem já lavou as mãos pode sentar, que já vou servir”. Todos correm para a mesa.

Nessa hora, a professora respeitou o limite imposto pela criança enquanto inserida num mundo de fantasias, com regras de dramatização de papéis implicitamente compreendidas pelo grupo participante da brincadeira de faz-de-conta. No grupo já existia um diretor de cena que coordenava o roteiro ou a trama, e muitas vezes parecia se importar com interferências abruptas do adulto, que tentava mudar a ordem das coisas.

Se o adulto sabe a hora certa de atuar, esses momentos são muito oportunos para a instrução da professora. Ela deve saber se colocar de forma a combinar o que será exposto com a brincadeira em si, ou com o que as crianças estão vivenciando no faz-de-conta. Em alguns episódios, a intervenção da professora foi vista pelas crianças de forma natural e demonstrou resultados, pois lhes mostrou de forma sutil alguns pontos, como a importância da cooperação entre as pessoas que vivem juntas em um grupo.

\section{Considerações finais}

Muitos estudos brasileiros sobre interação criança-criança, como os de Castro e Carvalho (1981), Moraes (1981), Lordelo (1985), Oliveira (1988), Pedrosa (1989), Perosa (1990), Garuti (1995) e Bastos (1995) têm apontado o quanto é importante esse tipo de relação interpessoal em locais onde há poucos adultos para lidar com muitas crianças pequenas.

O estudo da interação das crianças por meio da brincadeira de faz-de-conta responde algumas questões e fornece indícios que apontam o brinquedo - entendido aqui como qualquer forma de brincadeira, incluindo os jogos - como uma das mais importantes fontes propulsoras de ações sociais das crianças umas com as outras.

A representação e a construção de personagens vividas pelas crianças sugerem que elas tenham tido alguma vivência, ainda que curta, de situações como aquelas em que se encontram tais personagens. Os elementos para essas construções são buscados num arquivo de memórias que foram gravadas em algum momento de suas vidas.

O faz-de-conta vivido pela criança é fruto de sua participação num mundo cultural repleto de idéias, de sentidos, de valores e significados e, ainda, ampliado pelas suas características psicológicas como sujeito que cresce num determinado ambiente. Para Kishimoto (1997), o faz-de-conta infantil permite a entrada no imaginário da criança e a expressão de regras implícitas que se materializam nos temas das brincadeiras. O conteúdo do imaginário provém das várias experi- ências anteriores das crianças nos vários contextos sociais pelos quais ela já passou.

A interação criança-criança proporcionou a possibilidade de as crianças participarem da coordenação e da representação de papéis vinculados intimamente com episódios interativos já vividos anteriormente ou mesmo apenas observados por elas. Na maioria das vezes, as representações de papéis eram compostas por formas de interação já conhecidas pelas crianças ou permeadas por formas de condutas que para elas pareciam próprias dos papéis representados.

As crianças que participaram do estudo tinham histórias de vidas familiares conturbadas. Viviam em organizações familiares constituídas por várias pessoas diferentes, muitas vezes sem nenhum grau de parentesco ou consangüinidade, absorvidas por tensões do mundo cotidiano e principalmente pela miséria, alcoolismo e toxicomania. Apresentaram, entretanto, em suas brincadeiras, uma família harmoniosa.

Imersas num faz-de-conta aparentemente agradável, reproduziram um modelo de família visto muitas vezes à nossa volta. Viveram uma família nuclear harmoniosa, capaz de resolver seus conflitos como no modelo de família tradicional.

A família brincada dessas crianças talvez se aproxime muito pouco do que elas puderam viver em família. No entanto, são capazes de reproduzir tão fielmente o que seria o pai provedor, a mãe cuidadosa e vários irmãos juntos em volta de uma mesa de jantar. Nessa família todos os membros se respeitam, se ajudam e colaboram com o funcionamento geral do grupo. Todos podem compartilhar de uma mesa farta, com alimentos variados, que são servidos por uma mãe cuidadosa, que se empenha em atender a sua família com pratos e talheres limpos e bem conservados, arrumados cuidadosamente sobre a mesa, com a ajuda do pai.

A família apresentada por essas crianças foi formulada basicamente a partir da história humana de conhecimentos acumulados e de construções de idéias e modelos socialmente aceitos, fruto de um bem comum de nossa cultura ocidental, que, com o passar do tempo, é moldada pelas exigências de uma sociedade em transformação.

De acordo com Oliveira (1995),

(...) a brincadeira simbólica leva à construção pela criança de um mundo ilusório, de situações imaginárias onde objetos são usados como substitutos de outros, conforme a criança os emprega com gestos e falas adequadas. Nessa situação, a criança reexamina as regras embutidas nos atos sociais, as regulamentações culturais que fazem com que a mãe seja quem fica em casa enquanto o pai sai para o trabalho em certos grupos sociais. (p. 55)

A família brincada das crianças está na televisão, veiculada pelas novelas, desenhos animados (família Dinossauro, família Simpson, etc.), propaganda (família “margarina”), e encontrase também estampada em revistas, jornais e outdoors com fotografias de belas mães sorridentes, maridos encantadores, como príncipes, e filhos bem vestidos e bem tratados.

Livros didáticos e alguns textos religiosos também privilegiam esse tipo de organização familiar, que também é defendida pela professora ou monitora que acompanha as crianças no seu dia-a-dia e que lhes passa tudo isso como um modelo 
ideal a ser seguido. Além do mais, há uma conotação de valor associada à família organizada segundo o modelo preconizado pela sociedade mais ampla. Ser diferente, muitas vezes, é associado à incompetência (Szymanski, 1988).

Na brincadeira, entretanto, as crianças puderam viver momentos agradáveis e descontraídos, representando a família harmoniosa que aconchega os seus membros no calor do seu lar, oferece cuidados, amor e afeto que lhes são tão caros que, naquele momento, elas não podiam usufruir.

Apesar de haver a interferência de um adulto na brincadeira de faz-de-conta, as crianças se mostraram capazes, e desenvolveram, sozinhas, enredos próprios de uma situação familiar. O significado de cada papel e de cada ação das crianças foi expresso por elas mesmas na esfera imaginária da brincadeira de faz-de-conta, sendo apoiado em todos os elementos que elas tinham disponíveis em seu ambiente.

O grupo de crianças participantes deste estudo, assim como apontam estudos de Rossettti-Ferreira (1984) sobre o apego em creches de baixo nível socioeconômico, não se mostrou ser de crianças com baixa interação social, pois foram capazes de trocas sociais entre si e também com os poucos adultos que as rodeavam. Em suas brincadeiras demonstraram competência para a construção de enredos variados de faz-de-conta e em sua quase totalidade não eram apáticas e mostravam gostar de se envolver com o grupo, apesar de, às vezes, algumas crianças terem evidenciado em suas falas o desejo de estar com suas famílias.

Na Unidade Sampaio Viana, o funcionamento dos grupos de internos possibilita a união de irmãos de idades variadas nos mesmos dormitórios, como também a sua permanência durante todo o dia. A partir de 2 anos de idade, as crianças saem do berçário e podem se unir ao grupo de crianças maiores de até 8 anos, o que possibilita uma maior interação entre as crianças, gerando entre elas um espírito de ajuda mútua, cooperação e até o cuidado dos maiores com os menores.

Mesmo assim, não se pode deixar de fazer uma crítica à instituição que recebe as crianças de diferentes organizações familiares e coloca-as em grandes pavilhões como se fossem todas iguais, sem pensar na história de vida de cada uma e em suas diferenças individuais. Colocadas em grandes quartos com outras dezenas de crianças, acabam se tornando vítimas de um sistema falido, com pessoas mal preparadas para lidar com suas diferenças. Para complicar mais, não freqüentam nenhuma escola, não possuem atendimento pedagógico ou psicológico adequado e são cuidadas por um número irrisório de monitores sem formação específica, que, em sua maioria, acabam não atendendo às necessidades básicas das crianças, que, além de tudo, são privadas de um contato mais intenso com o mundo externo.

A questão do abandono é algo complexo, que vai muito além das necessidades meramente materiais de cada criança interna na instituição. O abandono afetivo e emocional é o que talvez seja o grande problema que acompanha a menoridade sob responsabilidade do Estado. Seria vital que as crianças que vivem numa instituição pudessem ter um adulto que as visse de forma singular, diferenciando-as do resto do grupo e mantendo com elas um vínculo. Isto é impossível de acontecer em complexos institucionais, com enormes pavilhões, onde são depositadas centenas de crianças com poucos adultos interagindo com elas.

Uma nova e possível forma de funcionamento das instituições deveria considerar a possibilidade de uma organização de grupos num formato semelhante ao da família - pequenos grupos, tendo adultos responsáveis com presença constante, incluindo crianças de várias faixas etárias e um acompanhamento individualizado -, o que possibilitaria uma condição de formação de vínculos afetivos entre criança-criança e adulto-criança, constituindo um contexto de desenvolvimento que favoreça interações múltiplas como aponta Bronfenbrenner (1979, 1998).

Favorecer a interação criança-criança, principalmente por meio das brincadeiras, significa expandir as possibilidades na educação de crianças pequenas, segundo Oliveira e Rossetti-Ferreira (1993). Com uma quantidade tão pequena de adultos para cada grupo de crianças, como é o caso da Febem, a solução possível seria privilegiar os contatos mais freqüentes entre crianças de idades variadas, obtendo, assim, um melhor aproveitamento das relações entre os grupos, melhorando a qualidade de vida das crianças que se encontram internas, privadas de contatos com sua família ou com o mundo externo.

Possibilitar momentos em que as crianças, juntamente com seus parceiros, possam, de forma prazerosa, externalizar situações imaginárias, transformar em ações lúdicas sentimentos e pensamentos, fazer a representação daquilo que elas acham que existe e trocar essas mesmas experiências com seus colegas, representa ampliar as possibilidades de se lidar com tantas crianças carentes de afeto e de vínculos pessoais num local com tão poucos recursos humanos. Explorar o imaginário infantil e as ações lúdicas de um grupo de crianças constitui uma excelente forma de se lidar com os afetos e as emoções das crianças, dando-lhes a oportunidade de se expressarem como sujeitos e de construírem, de forma conjunta e efetiva, sua personalidade.

A descoberta desta família brincada por essas crianças, que vivem sob responsabilidade do Estado, fornece indícios necessários para se acreditar que, apesar de estarem longe de suas famílias ou de não receberem carinho e educação adequados e ainda sofrerem discriminação por parte de uma sociedade que as vê como uma ameaça ou como um "caso perdido”, elas demonstram qualidades e habilidades sociais suficientes para, futuramente, se inserirem num contexto social mais amplo.

As habilidades sociais e as ações desenvolvidas pelas crianças na família brincada são a demonstração clara da capacidade de se tornarem pessoas respeitadas pela sociedade, aptas para o exercício de todas as condutas, atitudes e sentimentos que envolvem a vida social. Em suas brincadeiras, demonstraram o quanto estão inteiras para viverem a família brincada na prática da vida diária, construindo, futuramente, fora dos muros da instituição, uma família própria, tornando-se pessoas úteis e formadoras de outros sujeitos também aptos para contribuir para a sociedade em que estiverem inseridas.

A construção da idéia de família fornecida pela família brincada dessas crianças leva à reflexão sobre a urgência de 
se repensar os modelos de funcionamento institucionais oferecidos pelo Estado às crianças que possuem famílias ausentes. Parece ficar cada vez mais claro que, para a criança se desenvolver globalmente, necessita estar ligada a outras pessoas adultas ou que sejam mais experientes que ela, dando-lhes atenção, carinho e respeito, não necessariamente na família nuclear.

Este trabalho também aponta para a necessidade de se focalizarem os contextos de desenvolvimento, tal como aponta (Bronfenbrenner, 1979, 1998) privilegiando a participação da criança num maior número de ambientes possíveis, e em contato com diferentes pessoas, dando a elas oportunidades de interações variadas (díades, tríades, etc), em vez de centrarse tanto no modelo de família nuclear como sendo a única solução para o desenvolvimento infantil. Este atendimento poderá ocorrer em outros tipos de organização familiar e em instituições, desde que se considerem as necessidades biopsicossociais de crianças e adolescentes.

\section{Referências}

Ariès, P. (1981). História social da criança e da família. Rio de Janeiro: Zahar. (texto original publicado em 1973)

Badinter, E. (1985). Um amor conquistado: o mito do amor materno. Rio de Janeiro: Nova Fronteira.

Bastos, A. B. B. I. (1995). Interações e desenvolvimento no contexto sócio educativo da creche. Dissertação de Mestrado não-publicada, Pontifícia Universidade Católica de São Paulo, São Paulo.

Bowlby, J. (1981). Cuidados maternos e saúde mental. São Paulo: Martins Fontes. (texto original publicado em 1951)

Bronfenbrenner, U. (1979). The ecology of human development. Cambridge, Massachusetts: Harvard University Press.

Bronfenbrennner, U., \& Morris, P. A. (1998). The ecology of developmental processes. In W. Damon \& R. M. Lerner (Orgs.), Handbook of child psychology (Vol. I, pp. 993-1028). Nova York: Wiley.

Brougère, G. (1997). Brinquedo e cultura. São Paulo: Cortez.

Brougère, G. (1998). Jogo e educação. Porto Alegre: Artes Médicas.

Castro M. F., \& Carvalho, A. M. A. (1981). Incidentes agressivos na pré-escola. Revista de Psicologia, 7(2), 51-83.

Elkonin, D. B. (1998). Psicologia do jogo. São Paulo: Martins Fontes.

Freud, A., \& Burlingham, D. (1960). Meninos sem lar. Rio de Janeiro: Fundo de Cultura.

Fukui, L. (1981). A família em questão. Cadernos de Pesquisa, 37, 3-4.

Garutti, S. A. (1995). Interação criança-criança e criança-adulto: negociações da construção da linguagem escrita. Dissertação de Mestrado não-publicada, Pontifícia Universidade Católica de São Paulo, São Paulo.
Glaser, B. G., \& Strauss, A. L. (1967). The discovery of Grounded Theory. Nova York: Aldine.

Gomes, J. V. (1994). Socialização primária: tarefa familiar? Cadernos de Pesquisa, 9, 54-61.

Kishimoto, T. M. (1997). Jogo, brinquedo, brincadeira e a educação. São Paulo: Cortez.

Kishimoto, T. M. (1998). O brincar e suas teorias. São Paulo: Pioneira.

Leite, M. L. M. (1997). A infância no século XIX segundo memórias e livros de viagem. In M. C. de Freitas (Org.), História social da infância no Brasil (pp. 17-50). São Paulo: Cortez.

Lordello, E. R. (1985). Comportamento de cuidado entre crianças. Dissertação de Mestrado não-publicada, Universidade de São Paulo, São Paulo.

Marcílio, M. L. (1997). A roda dos expostos e a criança abandonada na história do Brasil. In M. C. de Freitas (Org.), História social da infância no Brasil (pp. 51-76). São Paulo: Cortez.

Mesgravis, L. (1976). Aassistência à infância desamparada e a Santa Casa de São Paulo: a roda dos expostos no século XIX. Revista de História, III(103), 401-423.

Moraes, M. L. S. (1981). O faz-de-conta e a realidade social da criança. Dissertação de Mestrado não-publicada, Universidade de São Paulo, São Paulo.

Oliveira, Z. M. R. (1988). Jogo de papéis: uma perspectiva para análise do desenvolvimento humano. Tese de Doutorado não-publicada, Universidade de São Paulo, São Paulo.

Oliveira, Z. M. R. (1995). A criança e seu desenvolvimento: perspectivas para se discutir a educação infantil. São Paulo: Cortez.

Oliveira, Z. M. R., \& Rossetti Ferreira, M. C. (1993). O valor da interação criança-criança em creches no desenvolvimento infantil. Cadernos de Pesquisa, 87, 62-70.

Pedrosa, M. I. P. de C. (1989). Interação criança-criança: um lugar de construção do sujeito. Tese de Doutorado não-publicada, Universidade de São Paulo, São Paulo.

Perosa, G. B. (1990). A creche e os estudos em desenvolvimento: análise dos contatos precoces entre pares. Tese de Doutorado não-publicada, Pontifícia Universidade Católica de São Paulo, São Paulo.

Poster, M. (1979). Teoria crítica da família. Rio de Janeiro: Zahar.

Rizzini, I. (1993). A assistência à infância no Brasil - uma análise de sua construção. Rio de Janeiro: Santa Úrsula.

Rossetti-ferreira, M. C. T. (1984.).O apego e as reações da criança à separação da mãe. Cadernos de Pesquisa, 48, 3-19.

Spitz, R. A. (1993). O primeiro ano de vida da criança. São Paulo: Martins Fontes. (texto original publicado em 1979)

Strauss, A., \& Corbin, J. (1990). Basics of qualitative research: grounded theory procedures and techniques. Londres: Sage.

Szymanski, H. R. G. (1987). Um estudo sobre significado de família. Tese de Doutorado não-publicada, Pontifícia Universidade Católica de São Paulo, São Paulo.

Szymanski, H. R. G. (1992). Trabalhando com famílias. São Paulo: Cortez e Centro Brasileiro para a Infância e Adolescência do Ministério da Ação Social.

Vygotsky, L. S. (1994). A formação social da mente. São Paulo: Martins Fontes.

\section{Nota}

1 Este trabalho tem por base parte da dissertação de mestrado da primeira autora, sob orientação da segunda, apresentada ao Curso de Pós-Graduação em Psicologia da Educação da Pontifícia Universidade Católica de São Paulo e contou com o apoio financeiro da CAPES.

Edna Martins, doutora em Psicologia da Educação pela Pontifícia Universidade Católica de São Paulo, é professora na Faculdade Ítalo-Brasileira de São Paulo. Endereço para correspondência: Av. Otacílio Tomanik, 1054, apto. 137 (Butantã); São Paulo, SP; CEP 05363-101. Fone: (11) 3714-8787. E-mail: martinsberbel@bol.com.br Heloisa Szymanski, doutora pela Pontifícia Universidade Católica de São Paulo, é professora no Programa de Pós-graduação em Psicologia da Educação da Pontifícia Universidade Católica de São Paulo. E-mail: hszymanki@uol.com.br 